\title{
Contextual Components of an Enterprise Architecture Framework for Pan-European e-Government Services
}

\author{
Ansgar Mondorf \\ University of Koblenz-Landau \\ mondorf@uni-koblenz.de
}

\author{
Maria A. Wimmer \\ University of Koblenz-Landau \\ wimmer@uni-koblenz.de
}

\begin{abstract}
Enterprise Architecture (EA) frameworks provide a wide range of architecture components. Contextual EA components provide the necessary guidance to design specific architectures in a given context e.g. for PanEuropean Government Services (PEGS). Contextual EA components help to describe the background and scope of architecture work and provide a ground to tackle architecture challenges in an agreed way. The main contribution of this conceptual paper is to connect existing theoretical models as a basis to examine contextual components of an EA framework for PEGS. Three aspects are elaborated using a model-based approach: a Critical Success Factor Model, a Strategy Management Model and a Stakeholder Engagement Model. The identified models are aligned with EA standards and provide guidance to empirical research and to programs, projects and initiatives that wish to create interoperability architectures.
\end{abstract}

\section{Introduction}

The European Commission refers to PEGS as a means to realize public service delivery across Member State borders. PEGS use various sources of information and are provided by different levels of public administrations [1]. Complexity, coordination and long term planning processes make it difficult to create sustainable PEGS. Organizations and departments have to rethink and reshape existing strategies, structures, processes, IT infrastructures and business models [2]. Many European countries have released e-government strategies to reduce interoperability barriers among governmental systems [3] but interoperability is still a major challenge. An appropriate design approach for PEGS is a critical factor to overcome these challenges.

Hjort-Madsen and Pries-Heje argue that governmental EA is a means to improve public service design [4]. However, there is no consensus about the shape of architecture components that can help to develop PEGS [2], [4]. Different frameworks, which vary in scope and specialization, are applied to develop governmental EAs [5]-[11]. A governmental EA may relate to government as a whole, to a particular domain or to an organizational context [12]. To effectively support the design and implementation of PEGS, key components of EA frameworks need to be identified and their relationships have to be discussed.

The paper uses the analytical structure proposed by the Content Context and Process (CCP) model to propose appropriate EA components. The CCP model was introduced to IS research by Symons (1991) [13] and has been applied in several studies (e.g. [14]). In relation to EA frameworks, the content dimension scopes 'what' constitutes the architecture design (e.g. specifications, standards, technologies). The context dimension addresses the background and scope of the envisioned architecture and elaborates the 'why' (e.g. political context, environment, strategic aspects). The process dimension describes the architecture governance and analyses the 'how' (e.g. EA management, standards life cycle, assessment methodologies). In this article, we focus on the context of an EA framework for PEGS using the following scientific frameworks as a basis.

Scholl et al. propose a framework to support process integration, information sharing, and system interoperation/interoperability (INT-IS-IOP). The framework reflects the need to identify stakeholder concerns and to settle project foci and purposes under consideration of the given limitation and constraints. The proposed approach ideally leads to the desired processes and outcomes [15], [16]. The model for multinational egovernment collaboration, information sharing and interoperability developed by Navarrete et al. integrates factors of INT-IS-IOP with a focus on interoperability challenges. The framework identifies four perspectives with subordinated factors: collaboration, value network models, border regions, and data integration [17]. The model of e-government interoperability of Flak \& SolliSaether explores contextual factors of interoperability activities. The model identifies actors, describes activities and reflects interoperability effects which are determined through evaluation approaches [18].

The frameworks propose a variety of contextual elements [16]-[18]. This work investigates several of the proposed elements with view to EA and PEGS. We propose three models based on an extensive review of literature in the field of e-government, EA and IS Research. First, a Critical Success Factor Model describes environmental constraints, project challenges 
and success factors. Then, a Strategy Management Model presents architecture design strategies and principles. Finally, a Stakeholder Engagement Model classifies stakeholders and identifies important drivers for their engagement.

The paper is organized as follows: Section 2 discusses literature in interoperability and EA research. Section 3 presents the research approach. Subsequently, the identified contextual components and models along the two selected EA standards are presented in section 4 . We conclude in section 5 with a discussion of limitations and needs for future work.

\section{Theoretical Background}

\subsection{Interoperability Research}

The creation of an EA framework for PEGS depends largely upon previous achievements of the European interoperability policy. The European interoperability policy is realized by a series of initiatives and instruments and helps to reach a consensus among Member States. The first phase (awareness building) relates to the establishment of the European Interoperability Strategy (EIS) and the European Interoperability Framework (EIF) [1], [19]. The EIS and EIF have stimulated the work on and adoption of several national interoperability frameworks [14], [20]. The EIS and EIF provide conceptual guidance for the creation of an European Interoperability Reference Architecture (EIRA) ${ }^{1}$ in phase two (establishment). The third phase (operation) initiates the use of EIRA while phase four (value adding) uses established architectures to improve public service delivery [1], [21], [22].

Current efforts are directed towards the establishment of EIRA and to initiate PEGS through large-scale pilot projects (LSPs). LSPs run in different areas such as e-health, e-procurement and e-justice. The e-SENS (Electronic Simple European Networked Services) ${ }^{2}$ project is an overarching LSP, which creates an European Interoperability Architecture across domains. e-SENS aims to consolidate, improve and extend the results of previous LSPs by using an architecture approach to construct and sustain core building blocks for interoperability.

Many authors point to challenges which relate to the construction of PEGS. There is a lack of guidelines that describe how to create, organize, use and comply with cross-border building blocks [22]-[24]. Interoperability among governmental institutions requires publication of commitments (methods, specifications, standards) that

\footnotetext{
${ }^{1}$ EIRA v1.00: https://joinup.ec.europa.eu/asset/eia/description

2 e-SENS: http://www.esens.eu/
}

describe the ways of interoperation beyond technical connectivity. There are practical problems on how to ensure an uptake of commitments, how to enable their evolvement and how to span trust across multiple organizations on the basis of commitments [2], [3], [16], [25]. Additionally, there are missing techniques that describe how to specify, implement and govern the information exchange between ICT systems and how to manage IT-supported relationships. [2], [3], [24], [26].

Interoperability projects need to manage several variables and factors beyond the technological view (e.g. resources, financial costs, legal restrictions, information security, incentives, market forces, knowledge [27]). Thus, projects like e-SENS need to negotiate with several stakeholders about the process to achieve interoperability. An anticipatory management of architecture outcomes is required in order to mitigate unwanted effects [16]. However, interoperability frameworks do not enable an anticipatory management. They prescribe the policies that governmental systems must comply with and therewith elaborate on the 'what' [21]. The objectives and contents of interoperability frameworks are often far too generic, abstract and static to be applied for service development, deployment and evolution. They do not reflect the 'how' and 'why' which provides the necessary methodological and analytical support for projects [20] [21]. EA frameworks are seen as a means to overcome these challenges [2].

\subsection{Enterprise Architecture Research}

EA frameworks support the process to develop, maintain and evolve a multidimensional approach, where interoperability is examined beyond technical connectivity considering social, political, cultural and legal factors as well [2], [5], [14], [16], [20], [28]-[30]. EA frameworks support a broad range of objectives and enable decision making on different levels. However, any EA adoption depends on stakeholder acceptance and appropriate architectural governance [2], [26], [28], [30]. EA needs to respond to social interdependencies [12] and has to be adjusted to the strategic, social and technological context in which the architecture is embedded [24].

EA frameworks provide several supporting components. The CCP dimensions offer the possibility to classify and characterize typical components of EA frameworks (cf. section 1). The TOGAF content framework [6] structures the content dimension or the 'what' along architecture viewpoints (e.g. business, information, application, technology) which establish conventions for architecture content [5]-[10], [31], [32]. Architecture description languages like ArchiMate help to create architecture models along the viewpoints [33], [34]. On the process dimension several EA frameworks 
are supported with life cycle models which enable EA planning and management [6], [8], [11]. Life cycle models support the 'how' and organize the architecture governance processes. TOGAF proposes the architecture development method (ADM) with guidelines for risk management, stakeholder management, etc. The TOGAF Architecture Capability Framework puts the appropriate organization structures, processes, roles and responsibilities in place [6].

The context of an EA framework defines the use and scope of the framework and elaborates the 'why'. EA frameworks address different contexts. While the Federal Enterprise Architecture Framework (FEAF) is specialized to U.S. Federal Government [11], TOGAF can be adapted to different contexts using the TOGAF enterprise continuum [6]. Levels of architecture scope describe the types of organizational complexity addressed by an EA framework [31] (e.g. Europeanwide or sector-specific for PEGS [1]). Primary outcomes represents areas of an EA framework where a direct, positive impact can be made [31] (e.g. service delivery, information exchange, cooperation, sharing, reuse and reduction of costs for PEGS [1]).

Moreover, EA frameworks comprise several basic elements, which ensure that EA programs are complete and effective [6], [31], [35]. Janssen et al identified four basic elements of governmental architectures [35]:

- Architecture principles describe strategic directions and guide information system design [6], [7], [35].

- Architecture guidelines determine recommended practice with some degree of freedom [35], [36].

- Standards or well-defined specifications establish commitments across organizations [7], [35].

- Common frameworks provide an analytical structure to develop architecture outcomes [32], [35], [37].

Basic elements establish conventions and contribute to the development of shared perspectives, commitments or common paths for interoperation [7], [32], [38].

The concepts of EA frameworks are often illustrated through meta models which describe the modeling concepts required to create architecture models [39]. In EA research, Zachman framework is likely the bestknown architecture meta model. It puts forward different perspectives on information systems, enterprise analysis and modelling [5]. ISO/IEC/IEEE 42010 [32] and IEEE 1471-2000 [37] are well-defined meta models for the development of architecture descriptions. The standards can be adapted to different contexts as shown in the further course of this work (cf. section 4).

\section{Research Approach}

The paper aims to synthesize interoperability research and EA research in the field of e-government to exploit the contextual dimension of an EA framework for PEGS. It is part of a larger research effort, which uses design science research for model development. The theory base is explored as follows [40]. At first requirements for an EA framework for PEGS were elaborated on the basis of a systematic literature review. The requirements were used to scope the core components of an EA framework for PEGS. While several requirements were addressed by existing EA frameworks, other requirements were not sufficiently addressed. The latter were defined as a gap [41]. Both, the identified components and gaps, were linked to the analytical structure of the CCP model (cf. section 1 and section 2.2) which serves as organizing framework [42].

The requirements analysis determined a number of gaps and concerns which are not yet addressed by EA frameworks [41]. The gaps scope a problem space in which the envisioned EA framework shall operate. They are used to determine, assess and customize appropriate EA components using the following methods: examining structure and qualities (static analysis), studying fit for purpose (architecture analysis) and optimizing properties and boundaries (optimization) of EA components [40]. The paper explores the gaps related to the contextual dimension in order to build a theoretical foundation for an EA framework for PEGS. This is done on the basis of the following research question: How can academic knowledge on various aspects of e-government, interoperability and EA be integrated into an EA framework in such a way that it meets the context of PEGS?

The exploration is done by conducting literature reviews for each gap. Literature reviews help to advance knowledge in IS research. By combining different fields of research, we synthesize concepts from various disciplines. The CCP model serves as organizing framework. It offers as a coherent structure and enables a structured analysis of gaps [42]. The gaps identified for the contextual dimension include: challenges, success factors, architecture principles, design strategies, stakeholder views and concerns. The results of the gap analysis are used to define three architecture models which are aligned with a conceptual model for the development of architecture descriptions [32] [37].

\section{Constructing an EA meta model for PEGS}

The ISO/IEC/IEEE 42010 [32] and IEEE 1471 [37] standards describe conceptual models for the creation, analysis and sustainment of architectures through the use of architecture descriptions (white concepts in figure 1). The authors describe the need to adapt the models to a desired context [20], [21]. Figure 1 shows an adaption to PEGS using three model extensions. Together they 
constitute an EA meta model for PEGS. The relationship between the standards, the gaps (cf. section 3) and the proposed model extension is illustrated together with a subordinated research question.

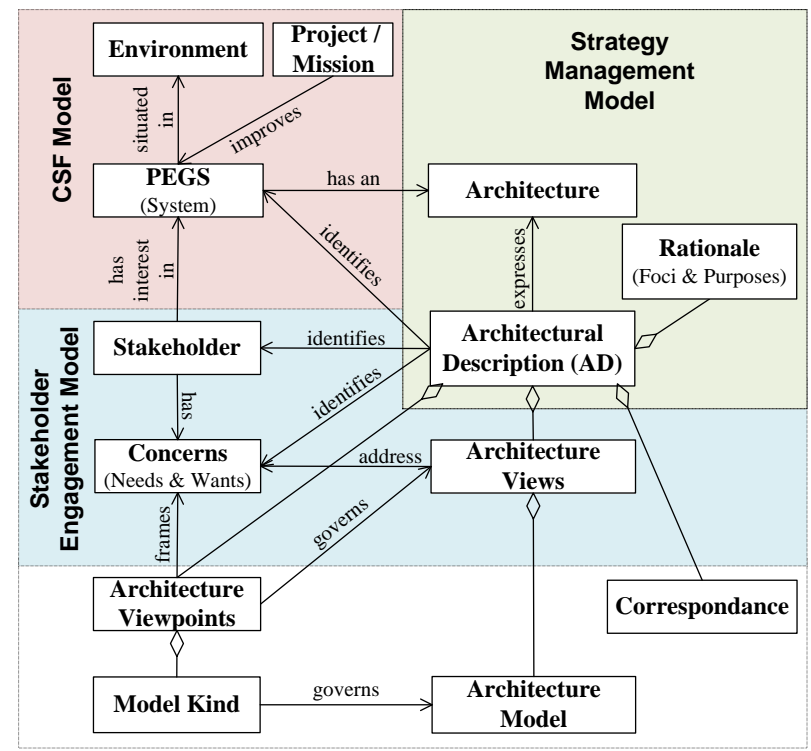

Figure 1: EA Meta model for PEGS acc. to [32], [37]

The CSF Model: Systems like PEGS are situated in an environment. PEGS are improved by projects on the basis of a defined mission [32], [37]. Contextual factors of e-government interoperability like laws, politics, collaboration abilities [18] constrain the environment and lead to numerous project challenges [15]-[17]. Section 4.1 proposes a Critical Success Factor (CSF) Model which helps to navigate interoperability projects around typical pitfalls. It helps to answer the following research question. Which contextual factors and challenges constrain the creation of PEGS? Which success factors help to control these challenges?

The Strategy Management Model: Systems like PEGS have an underlying architecture which is expressed through a set of architecture descriptions. Amongst others, architecture descriptions document the rationales (foci and purposes) behind architecture decisions (e.g. the basis for a decision, sources, alternatives) [32], [37]. Interoperability activities like standardization, technical integration and governance [18] outline reasonable foci and purposes which can be institutionalized through principles and strategies [15], [16]. Section 4.2 proposes a Strategy Management Model which facilitates decision-making for PEGS. It helps to define architecture rationales and integrates the following aspects: Which principles guide the design of PEGS? Which strategic considerations provide a foundation for identifying rationales of an architecture?
The Stakeholder Engagement Model: Stakeholders can adopt different roles during the provision of PEGS. While roles help to determine and classify stakeholder concerns (needs and wants), architecture views aggregate a related set of concerns. Views and concerns should be reflected in architecture descriptions [32], [37]. The consideration of needs and wants from stakeholders like policy makers, users or service providers increases stakeholder acceptance and is a driver for interoperability projects [15], [16], [18]. Section 4.3 defines a Stakeholder Engagement Model which classifies stakeholders, roles and business drivers to create meaningful architectures views. It explores the following research questions: Which stakeholders and concerns exist in PEGS? Which concerns can serve as driver for interoperability projects?

The EA standards introduce four additional concepts. The concepts belong to the content dimension of EA frameworks (cf. section 2.2). Architecture viewpoints establish conventions (e.g. notations, model kinds, rules, methods) for constructing architecture views. Architecture views are built from architecture models. Model kinds provide conventions for creating architecture models. Thus, a view is governed by its viewpoint whereas model kinds governing the creation of architecture models. Correspondences describe the relations between elements (e.g. architecture models) of architecture descriptions [20], [21]. The four additional concepts on the content dimension are considered to be out of the scope for this analysis and point to future research needs of an EA framework for PEGS.

\subsection{Managing Challenges and Success Factors}

This section describes constraints, challenges and critical success factors (CSF) for PEGS. The consideration of these factors affects project success and failure. Figure 2 shows a CSF Model that illustrates the influence of challenges, constraints and success factors.

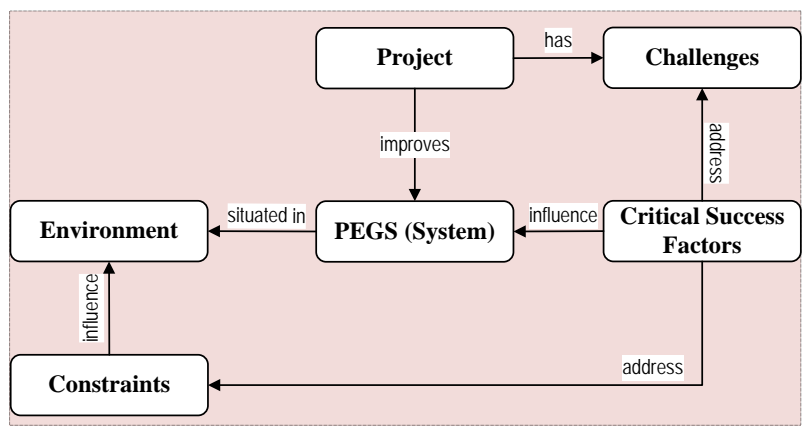

Figure 2: The CSF Model

The knowledge about environmental constraints and project challenges supports managers to react early in 
the process with appropriate actions. Multiple authors have investigated environmental constraints for interoperability from different perspectives [16], [17], [43], [44]. A comprehensive selection of environmental constraints and appropriate actions to counteract is proposed by Scholl \& Klischewski [16]. The following list shows constraints together with corresponding success factors. The success factors are qualified through further literature reviews:

- Constitutional: Clear vision, political will \& clear constitutional boundaries [16], [17], [44]

- Jurisdictional: Strengthen commitment through awareness building, engagement \& imposition of jurisdictional authorities [16], [17], [44]

- Collaboration: Ensure compatible visions, trust \& collaboration ability [3], [16], [17], [22]

- Organizational: Use common standards \& policies to establish similar contexts [16], [17], [45]

- Informational: Harmonization of quality, privacy \& security standards [3], [16], [17], [43], [44]

- Managerial: Harmonization of needs/interests \& mutual recognition of legacy [3], [16], [17], [44]

- Financial: Commitment of resources, balance of ambitions and cost [3], [16], [17], [43], [44]

- Technological: Encourage use of \& adherence to modern standards [3], [16], [17], [43], [44]

- Performance: Built few effective interoperations \& consider ability to scale up later on [3], [16], [17]

A similar approach is used for defining project challenges and corresponding success factors:

- Measurement of success \& failure: Agreement on success \& failure metrics [15]

- Management of funds \& risks: Tight steering/ awareness of funds/risks, in-house funds [43], [46]

- Interdependencies among actors: Formalized relationships (federations) [15], [43], [46]

- Opposing goals: Shared vision, alignment of stakeholder needs \& wants [15], [43], [44], [46]

The identified success factors are further structured using CSF approaches of EA frameworks. Nikpay et al. compare various CSF approaches of EA implementation projects and identify relevant categories of CSF in EA frameworks [47]. The success factors above are mapped to these categories in order to build a comprehensive structure of CSFs (cf. table 1). The CSF Model integrates this structure and scopes how to tackle environmental constraints and project challenges in interoperability projects. The CSFs support architecture planning processes for PEGS and point to relevant pitfalls and targets. Architecture planning processes require a deep understanding of the context, the stakeholders and their capacities [15], [44]. The model helps managers to achieve an understanding of the challenges early in the planning process and to react with appropriate actions.

Table 1: CFSs of an EA framework for PEGS

\begin{tabular}{ll}
\hline Category & CFS \\
\hline Governance & -Mutual recognition of existing solutions \\
& -Binding collaboration agreements \\
& -Support of jurisdictional authorities \\
& -Political will \\
& -Trust \\
\hline Stakeholder & -Strong underlying commitments \\
participation & -Similar organizational context \\
& -Commitment of resources \\
& -Collaboration abilities \\
\hline Communication & -Respect of constitutional boundaries \\
\& Support & -Alignment of needs and wants \\
& -Compatible visions \\
& -Clear vision \\
\hline Planning & -Agreed level of information quality, \\
& privacy \& security \\
& -Agreement on \& adherence to modern \\
& standards \\
& -Few effective interoperations \\
& -Scalable solutions \\
\hline Management & -Balance of ambitions \& cost constraints \\
& -Defined success and failure metrics \\
& -Steering of funds and risks \\
\hline
\end{tabular}

\subsection{Managing Strategies and Principles}

This section describes principles and strategies which support PEGS provision. The EIF defines generic principles of PEGS which provide a general frame of reference [1]. The principles of the EIF describe the context in which PEGS are decided and therewith determine rationales for architecture choices. However, e-government strategy on interoperability is scattered and has multiple facets.

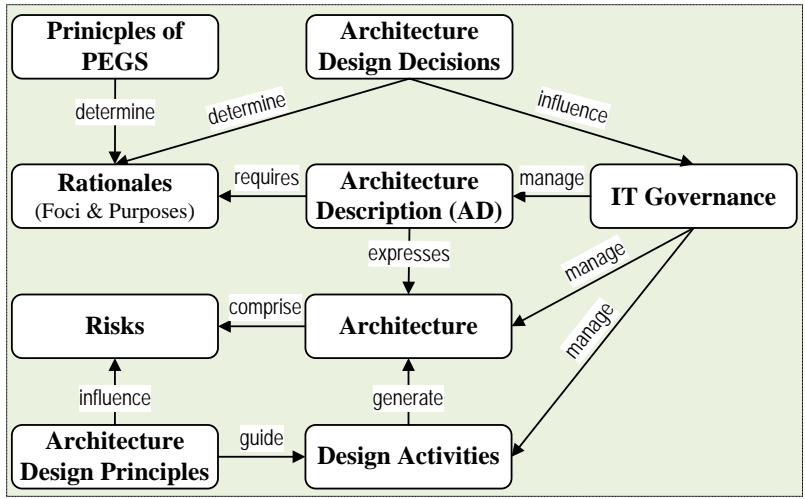

Figure 3: Strategy Management Model

Klischewski has shown how governance of interoperability is established through a defined interoperability strategy. The author suggests to 
deliberate upon strategic design directions and to base interoperability on clear architecture design decisions that enable actors to follow the same architecture vision [24]. Architecture design decisions are made on the basis of strategic considerations and the Strategy Management Model illustrates how to capture such rationales (foci \& purposes) for architecture descriptions (cf. figure 3). Rationales are derived from both, the principles of PEGS and architecture design decisions. Several authors have reasoned about design strategies in interoperability projects (e.g. [24], [30], [48]). However, there is no ultimate proposition of an architecture design strategy for PEGS. Strategic considerations should include the comparison of positive with negative effects along a given scenario, stakeholder needs and other environmental factors. Such reasoning may also lead to a combination of the following approaches:

- Top-down and/or bottom-up approach: A top down approach requires strong central leadership and decision-making power that are weak on European level. Thus, top-down innovation and diffusion processes should be complemented by bottom-up approaches. A bottom-up approach fosters general acceptance of solutions but depends upon appropriate financial support [19], [24], [48].

- Open processes and/or open specifications: The involvement of public administration is a key to the alignment of requirements and the acceptance of specifications and standards. Open processes help to consider stakeholder concerns but they might become a burden for interoperability projects. Open specifications provide solid ground for innovation, growth and fair competition when they are built on consensus, openness and transparency [1], [49], [50].

- Standardization and/or centralization: Standardization and centralization are fundamental strategies to realize PEGS. Standardization of interfaces for electronic data exchange is in favor when centralization is political/legally not possible. Standardization requires the ability of each organization to have its own processing capability (e.g. business processes, interfaces, applications). Centralization requires a strong political will, central governance and often implicates changes of authority and jurisdiction. Centralized capabilities are also required to provide functions for a standardized data exchange (e.g. address translation, message routing, authentication ) [18], [28], [30], [45], [51].

- Organizational integration and/or technical integration: Modularity and a loose coupling of systems are central concern of organizational integration. Organizational integration aims to achieve business process alignment and modular interface architecture within domains and therefore differentiates between private and public processes.
[16], [18], [23], [48]. Technical integration is realized through infrastructure services, which are reused across processes and domains. Reusable building blocks are key enablers for interoperability that facilitate convergence and technical integration of IT solutions. Reference architectures and open source software illustrate solution development and provide a foundation for multiple organizations [18], [19], [24], [36], [49], [50]. Both strategies can be combined with standardization activities.

The strategic considerations above help to make architecture design decisions that set foci and purposes in interoperability projects. However, every architecture design decision also influences the management of architectures (IT Governance). IT governance describes how architectures are organized, managed and maintained over time. The governance of IT solutions is dependent on the ability to make top-down decisions, the impact of open processes or the degree of standardization. Standardization for examples requires specific governance settings. While technical standards are mostly defined by national/international standardization committees, organizational standards are created by industrial or sector-specific organizations [28], [30].

EA frameworks such as TOGAF propose to define architecture principles for design activities as well [6]. Architecture design principles close performance gaps, promote stakeholder engagement, increase reusability or eliminate duplication [11]. Janssen \& Kuk outline comprehensive architectural design principles for complex e-government projects which need to consider various interoperability problems. Their findings are grouped into the following three areas [48]:

- Control of diversity: constrain diversity and define a clear target space.

- Concertation of activities: foster best practices, promote reusability and facilitate modularity.

- Increase of interaction: stimulate sharing, develop competencies and facilitate coalitions.

Janssen \& Kuk note that most projects fail to implement corresponding principles. The authors' further state that these principles are supportive to build a common vision, strategy and path for development because they concentrate activities and help to increase the interaction and engagement of participants [48].

\subsection{Stakeholder Engagement and Management}

Stakeholder management ensures the establishment of a shared architecture vision and is a key concern of interoperability projects. It helps to reveal, systemize and control relevant collaboration networks and crossorganizational relationships. Thus, stakeholder management is a fundamental mechanism to establish 
consensus among stakeholders and to ensure appropriate commitment and buy-in when realizing PEGS [19].

Flak \& Rose show how to adopt stakeholder theory in e-government [26]. A socio-political perspective helps to understand how collaboration and engagement is achieved in governmental EA projects [12]. EA frameworks use architecture views to identify relevant perspectives and to aggregate a related set of concerns [5], [6], [11]. The Stakeholder Engagement Model (cf. figure 4) systemizes the different roles of stakeholders in interoperability projects and supports the process to determine appropriate architecture views for PEGS.

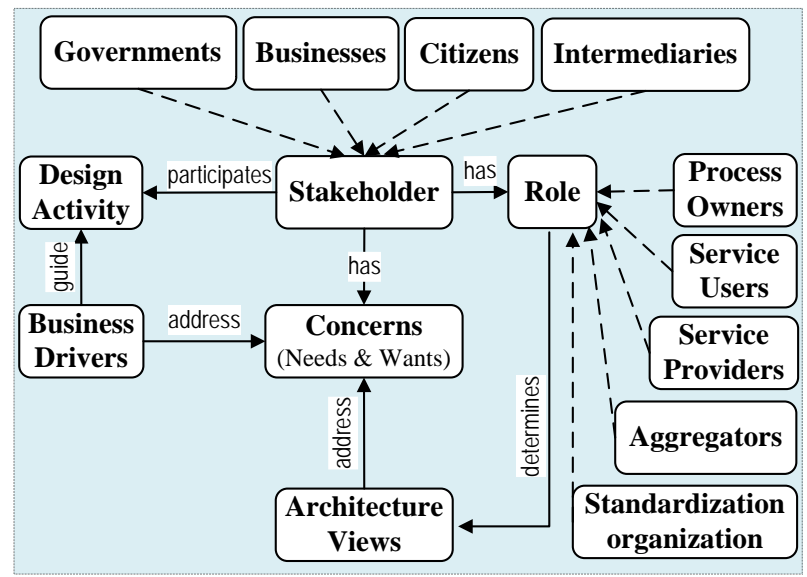

Figure 4: Stakeholder Engagement Model

Stakeholder classification is an approach to identify meaningful stakeholder groups. The identification of meaningful stakeholder groups is a methodological and practical challenge because actors can adapt several roles at the same time. Misuraca et al. distinguish between users and operators of services [52]. Klischewski \& Scholl adapted a stakeholder model, which separates between service users, public administrations and IT developers. The authors associate intermediaries and service providers to the class of public administration [53]. Flak \& Solli-Saether distinguish between policy makers, government employees, service users and legislators but do not consider intermediaries and service providers [18].

Table 2 uses the different approaches [18], [52], [53] to proposes a consolidated stakeholder classification for PEGS. The proposed classification system starts from four major stakeholder groups and leads to distinct but recurring roles. Governments are key players to PEGS but there is a wide range of actors (e.g. European Commission, Member States, public administrations, employees) with varying roles. Some roles (e.g. service users, service providers) can be adopted from businesses as well. Lueders underpins the need for effective collaboration networks that consist of partnering between governments and businesses. Businesses play a significant role to reduce risks (e.g. adoption of standards in private sector, market support, technology advances, business process improvements) [49]. Businesses and Citizens are typical users of the defined services. Intermediaries are a heterogeneous group with different access to PEGS. Standardization organizations are probably the most important subgroup in this area.

Table 2: Stakeholders and their roles

\begin{tabular}{|c|c|c|}
\hline Groups & Roles & \begin{tabular}{|l} 
Description \\
\end{tabular} \\
\hline \multirow{3}{*}{ 莺 } & $\begin{array}{l}\text { Process } \\
\text { Owners }\end{array}$ & $\begin{array}{l}\text { In this role governments act as } \\
\text { policy makers, legislators and } \\
\text { facilitators of projects etc. }\end{array}$ \\
\hline & Service Users & $\begin{array}{l}\text { In this role public } \\
\text { administrations execute G2B, } \\
\text { G2G or G2C communications. }\end{array}$ \\
\hline & $\begin{array}{l}\text { Service } \\
\text { Providers }\end{array}$ & $\begin{array}{l}\text { In this role public } \\
\text { administrations provide services } \\
\text { to other (public) agencies. }\end{array}$ \\
\hline \multirow{2}{*}{ 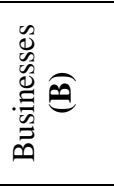 } & Service Users & $\begin{array}{l}\text { In this role businesses execute } \\
\text { G2B communications. }\end{array}$ \\
\hline & $\begin{array}{l}\text { Service } \\
\text { Providers }\end{array}$ & $\begin{array}{l}\text { In this role businesses provide } \\
\text { services to other public or } \\
\text { private agencies. }\end{array}$ \\
\hline $\begin{array}{l}\text { Citizens } \\
\text { (C) }\end{array}$ & Service Users & $\begin{array}{l}\text { In this role citizens execute } \\
\text { G2C communications }\end{array}$ \\
\hline \multirow{3}{*}{ 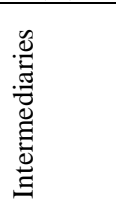 } & $\begin{array}{c}\text { Standards } \\
\text { organizations }\end{array}$ & $\begin{array}{l}\text { Facilitation of open processes } \\
\text { and open standards. }\end{array}$ \\
\hline & Aggregators & $\begin{array}{l}\text { Collection of information from } \\
\text { multiple sources for further use. }\end{array}$ \\
\hline & $\begin{array}{l}\text { Interest } \\
\text { Groups }\end{array}$ & $\begin{array}{l}\text { Influencing discussions in } \\
\text { stakeholder groups. }\end{array}$ \\
\hline
\end{tabular}

Stakeholder classes help to determine appropriate architecture views for PEGS. However, architecture views should be based on further factors that determine the importance of individual stakeholders on the basis of their legitimacy to act, their overall power and the urgency of claims [6], [53], [54].

The consideration of business drivers for architecture views helps to create effective stakeholder engagement strategies. Business drivers are crucial factors to influence stakeholder engagement positively. They provide a motivation for collaboration and clarify the goals of architecture work [6], [21]. Table 3 compares business drivers of interoperability projects on the basis of three scientific contributions [15], [21], [55]. Where possible, a ranking is provided in brackets (drivers with highest average ranking are in the upper part of table 3). Scholl et al. identify stakeholder needs and wants from the analysis of several interoperability projects [15]. Penttinen \& Isomäki interviewed participants of interoperability initiatives in various sectors and different levels of government [55]. Gøtze et al. assessed the effect of business drivers for the engagement of stakeholders into interoperability projects [21]. All authors summarize that the identified drivers increase 
the performance of projects and support the agreement on goals and objectives [15], [21], [55].

Table 3: Drivers for Stakeholder Engagement

\begin{tabular}{lll}
\hline Gøtze et al. [21] & Scholl et al. [15] & $\begin{array}{l}\text { Penttinen \& } \\
\text { Isomäki [55] }\end{array}$ \\
\hline $\begin{array}{l}\text { Improved service } \\
\text { delivery (2) }\end{array}$ & $\begin{array}{l}\text { Service enhancement } \\
(1)\end{array}$ & $\begin{array}{l}\text { Better } \\
\text { services }\end{array}$ \\
\hline $\begin{array}{l}\text { Support \& enable } \\
\text { business change (3) }\end{array}$ & $\begin{array}{l}\text { Modernization of } \\
\text { administrations }\end{array}$ & New services \\
\hline $\mathrm{n} / \mathrm{a}$ & $\begin{array}{l}\text { Security \& reliability } \\
(2)\end{array}$ & $\mathrm{n} / \mathrm{a}$ \\
\hline $\begin{array}{l}\text { Cross-governmental } \\
\text { interoperability (1) }\end{array}$ & $\begin{array}{l}\text { Effective data } \\
\text { collection \& } \\
\text { exchange (3) }\end{array}$ & $\begin{array}{l}\text { Interoperability } \\
\text { \& shared } \\
\text { services }\end{array}$ \\
\hline $\begin{array}{l}\text { Improve process } \\
\text { effectiveness (5) }\end{array}$ & $\begin{array}{l}\text { Reduce workload \& } \\
\text { time savings (4) }\end{array}$ & $\begin{array}{l}\text { Efficiency } \\
\text { improvement }\end{array}$ \\
\hline n/a & $\begin{array}{l}\text { Ease of use \& } \\
\text { handling (5) }\end{array}$ & $\begin{array}{l}\text { Customer } \\
\text { viewpoint }\end{array}$ \\
\hline n/a & $\begin{array}{l}\text { Standardization \& } \\
\text { Alignment (6) }\end{array}$ & $\begin{array}{l}\text { Coherent } \\
\text { processes }\end{array}$ \\
\hline $\begin{array}{lll}\text { Greater business } \\
\text { process flexibility (4) }\end{array}$ & Adaptability (13) & n/a \\
\hline n/a & $\begin{array}{l}\text { Information quality } \\
\text { (7) }\end{array}$ & $\begin{array}{l}\text { Common } \\
\text { information } \\
\text { resources }\end{array}$ \\
\hline n/a & Secure identification & n/a \\
\hline Reduce time and \\
costs for IT (7) (8)
\end{tabular}

\section{Conclusions}

EA is a way to progress interoperability in egovernment. Interoperability projects require an effective management of architecture solutions. EA frameworks provide means for architecture development and describe ways how to ensure the sustainability of architectures beyond a project lifetime. However, there is a variety of views on the EA concept in e-government. Architecture has various meanings depending on its contextual usage. The paper at hand presents contextual factors of an EA framework PEGS. The factors are elaborated through literature reviews and demonstrate a level of consensus that exists upon a uniform definition of an EA framework for PEGS.

The investigation has shown that many interoperability issues on the contextual dimension are well described in the literature. However, their relation to EA frameworks is sometimes unclear. The integration of interoperability research into disciplines like EA has the potential to increase the level of support for interoperability projects. The three proposed models provide such guidance and help to create EAs for PEGS. They are built on relevant EA concepts and integrate contextual factors for interoperability (e.g. challenges, success factors, strategies, stakeholders, drivers) to generate desired outcomes in interoperability projects.

The achieved results have certain limitations. Even though the contextual factors were identified by combing techniques such as literature review and requirements analysis, the usefulness of the proposed components has not been approved in a separate process. A demonstration of the proposed conceptual models in the domain of eProcurement is planned for the future. Future work should also provide further insights into model elements and their relations. For interoperability projects it would be for example interesting to detail how architecture design decisions influence the governance of architectures. Then, appropriate governance structures could be established early in the EA management process. The provision of architecture view templates for PEGS that are build on well-defined set of modelling techniques and view-specific concerns is another potential improvement.

A proper EA framework for PEGS should also reflect content-oriented and process-oriented aspects of interoperability. Both dimensions are a matter of future research as well (cf. chapter 3 or [41]). When comparing the three CCP dimensions with EIRA (cf. section 2.2), it can be reflected that EIRA rather focuses on contentrelated aspects. Thus, the work at hand can be used in addition to EIRA and increases the support for adopters because it describes a complementary dimension.

\section{Acknowledgement}

This work has been conducted in the context of the eSENS project which is co-funded by the EU ICT Policy Support Programme (ICT PSP) under the Competitiveness and Innovation Framework Programme (CIP).

\section{References}

[1] European Commission, "European Interoperability Framework (EIF) for European public services,” COM(2010) 744 final, European Commission, Brussels, p. 40, 2010.

[2] M. Janssen, Y. Charalabibis, G. Kuk, and T. Cresswell, “Guest Editors' Introduction: E-government Interoperability, Infrastructure and Architecture: State-of-the-art and Challenges,” J. Theor. Appl. Electron. Commer. Res., vol. 6, no. 1, pp. I-VIII, Apr. 2011.

[3] C. Legner and K. Wende, "Towards an Excellence Framework for Business Interoperability,” in Proceedings of the 19th Bled eConference "eValues," 2006. 
[4] K. Hjort-Madsen and J. Pries-Heje, "Enterprise Architecture in Government: Fad or Future?," 42nd Hawaii International Conference on System Sciences (HICSS-42). Waikoloa, Big Island, Hawaii, p. 132 (1-10), 2009.

[5] J. A. Zachman, “A framework for information systems architecture,” IBM Syst. J., vol. 26, no. 3, pp. 276-292, 1987.

[6] The Open Group, “TOGAF Version 9.1,” 2011. [Online]. Available: http://pubs.opengroup.org/architecture/togaf9doc/arch/. [Accessed: 15-Jun-2016].

[7] F. J. Armour, S. H. Kaisler, and S. Y. Liu, "A big-picture look at enterprise architectures,” IEEE IT Prof., vol. 1, no. 1, pp. 35-42, 1999.

[8] F. J. Armour, S. H. Kaisler, and S. Y. Liu, "Building an Enterprise Architecture Step by Step,” IEEE IT Prof., vol. 1, no. 4, pp. 31-39, 1999.

[9] F. J. Armour and S. H. Kaisler, "Enterprise architecture: agile transition and implementation,” IT Prof., vol. 3, no. 6, pp. 30-37, 2001.

[10] S. Spewak and M. Tiemann, "Updating the Enterprise Architecture Planning Model,” J. Enterp. Archit., vol. 2, no. May, pp. 11-19, 2006.

[11] US Office of Management and Budget, "The Common Approach to Federal Enterprise Architecture,” Office of Management and Budget. The White House, p. 52, 2012.

[12] M. Janssen, "Sociopolitical Aspects of Interoperability and Enterprise Architecture in E-Government," Soc. Sci. Comput. Rev., vol. 30, no. 1, pp. 24-36, Jan. 2012.

[13] V. J. Symons, "A review of information systems evaluation: content, context and process,” Eur. J. Inf. Syst., vol. 1, no. 3, pp. 205-212, 1991.

[14] D. Ray, U. Gulla, S. S. Dash, and M. P. Gupta, “A critical survey of selected government interoperability frameworks," Transform. Gov. People, Process Policy, vol. 5, no. 2, pp. 114-142, 2011.

[15] H. J. Scholl, H. Kubicek, R. Cimander, and R. Klischewski, "Process integration, information sharing, and system interoperation in government: A comparative case analysis,” Gov. Inf. Q., vol. 29, no. 3, pp. 313-323, 2012.

[16] H. J. Scholl and R. Klischewski, “E-Government Integration and Interoperability: Framing the Research Agenda,” Int. J. Public Adm., vol. 30, no. 8-9, pp. 889-920, Jul. 2007.

[17] C. Navarrete, J. R. Gil-Garcia, S. Mellouli, T. A. Pardo, and H. J. Scholl, "Multinational E-Government Collaboration, Information Sharing, and Interoperability: An Integrative Model," in 43rd Hawaii International Conference on System Sciences (HICSS-43), 2010, pp. 1-10.

[18] L. S. Flak and H. Solli-Saether, "The Shape of Interoperability: Reviewing and Characterizing a Central Area within eGovernment Research," in 45th Hawaii International Conference on System Sciences (HICSS-45), 2012, pp. 26432652.

[19] European Commission, "European Interoperability Strategy (EIS) for European public services.” European Commission, Brussels, pp. 1-8, 2010.

[20] Y. Charalabidis, F. Lampathaki, and D. Askounis, “A Comparative Analysis of National Interoperability Frameworks," 15th Americas Conference on Information Systems (AMCIS 2009), vol. Paper 694. AIS, San Francisco, CA, pp. 1-10, 2009.

[21] J. Gøtze, P. E. Christiansen, R. K. Mortensen, and S. Paszkowski, "Cross-National Interoperability and Enterprise Architecture,” Informatica, vol. 20, no. 3, pp. 369-396, 2009.

[22] J. I. Criado, “Interoperability of eGovernment for Building Intergovernmental Integration in the European Union,” Soc. Sci. Comput. Rev., vol. 30, no. 1, pp. 37-60, 2012.

[23] J. Ziemann, Architecture of Interoperable Information Systems - An Enterprise Model-Based Approach for Describing and Enacting Collaborative Business Processes. Berlin: Logos Verlag, 2010.

[24] R. Klischewski, "Architectures for tinkering? Contextual strategies towards interoperability in E-government,” J. Theor. Appl. Electron. Commer. Res., vol. 6, no. 1, pp. 26-42, 2011.

[25] P. H. Kubicek, "Governance of Interoperability in Intergovernmental Services Towards an Empirical Taxonomy," in Proceedings of the 2nd International MultiConference on Society, Cybernetics and Informatics, Volume III, 2008, pp. 100-105.

[26] L. S. Flak and J. Rose, "Stakeholder Governance: Adapting Stakeholder Theory to E-Government,” Commun. Assoc. Inf. Syst., vol. 16, pp. 642-664, 2005.

[27] E. M. dos Santos and N. Reinhard, "Barriers to Government Interoperability Frameworks Adoption,” in 16th Americas Conference on Information Systems (AMCIS 2010), 2010, pp. 1-10.

[28] H. J. Scholl, H. Kubicek, and R. Cimander, "Interoperability, Enterprise Architectures, and IT Governance in Government," in Electronic Government, vol. 6846, M. Janssen, H. J. Scholl, M. A. Wimmer, and Y. Tan, Eds. Berlin, Heidelberg: Springer Berlin Heidelberg, 2011, pp. 345-354.

[29] L. Guijarro, “Interoperability frameworks and enterprise architectures in e-government initiatives in Europe and the United States,” Gov. Inf. Q., vol. 24, no. 1, pp. 89-101, 2007.

[30] H. Kubicek and R. Cimander, "Three dimensions of organizational interoperability: Insights from recent studies for improving interoperability frameworks,” Eur. J. ePractice, no. 6, pp. 3-14, 2009.

[31] US Office of Management \& Budget, "Federal Enterprise 
Architecture Framework - Version 2.” The White House, pp. 1-434, 2013.

[32] ISO/IEC/IEEE, "Systems and software engineering Architecture Description (ISO/IEC/IEEE 42010),” vol. 2011. ISO/IEC/IEEE, p. 46, 2011.

[33] M. M. Lankhorst, H. a Proper, and H. Jonkers, “The Architecture of the ArchiMate Language," in Enterprise, Business-Process and Information Systems Modeling, vol. 29, Springer, 2009, pp. 367-380.

[34] The Open Group, “ArchiMate 2.1 Specification.” The Open Group, Berkshire, p. 181, 2013.

[35] M. Janssen, L. S. Flak, and Ø. Sæbø, “Government Architecture: Concepts, Use and Impact," in Electronic Government, M. A. Wimmer, M. Janssen, and H. J. Scholl, Eds. Springer Berlin Heidelberg, 2013, pp. 135-147.

[36] R. Cloutier, G. Muller, D. Verma, R. Nilchiani, E. Hole, and M. Bone, "The Concept of Reference Architectures," J. Syst. Eng., vol. 13, no. 1, pp. 14-27, 2010.

[37] Architecture Working Group, “IEEE Std 1471-2000 Recommended Practice for Architectural Description of Software-Intensive Systems, I.S.E.S,” Ieee, Washington, D.C., 2000.

[38] R. Winter and R. Fischer, "Article Essential Layers , Artifacts , and Dependencies of Enterprise Architecture,” J. Enterp. Archit., vol. 3, no. 2, pp. 7-18, 2007.

[39] C. Braun and R. Winter, "A comprehensive enterprise architecture metamodel and its implementation using a metamodeling platform," in Proceedings of 1st International Workshop on Enterprise Modelling and Information Systems Architectures, 2005, pp. 64-79.

[40] A. R. Hevner, S. T. March, J. Park, and S. Ram, “Design Science in Information Systems Research,” MIS Q., vol. 28, no. 1, pp. 75-105, 2004.

[41] A. Mondorf and M. A. Wimmer, "Requirements for an Architecture Framework for Pan-European E-Government Services," in Electronic Government - Proceedings of the 15th International Conference ( EGOV 2016), Guimarães, Portugal, 2016, pp. 135-150.

[42] J. Webster and R. Watson, “Analyzing the past to prepare for the future: Writing a literature review,” Manag. Inf. Syst. Q., vol. 26, no. 2, pp. xiii-xxiii, 2002.

[43] K. O. Ondimu and G. M. Muketha, "Challenges in Achieving Interoperability in Distributed Systems : a Survey of Literature,” Int. J. Emerg. Sci., vol. 2, no. December, pp. 619630, 2012.

[44] S. Archmann and M. M. Nielsen, "Interoperability and Its Importance to eGovernment - Success Factors and Barriers," 2nd International Conference on Methodologies, Technologies and Tools Enabling e-Government (MeTTeG 2008). Halley Editrice, Corfu, Greece, pp. 1-12, 2008.

[45] R. Klischewski, “Information Integration or Process Integration? How to Achieve Interoperability in Administration," Electronic Government: 3rd International Conference (EGOV 2004), vol. 3183. Springer, Berlin / Heidelberg, pp. 57-65, 2004.

[46] A. S. Hellberg and A. Gronlund, "Conflicts in implementing interoperability: Re-operationalizing basic values,” Gov. Inf. Q., vol. 30, no. 2, pp. 154-162, 2013.

[47] F. Nikpay, H. Selamat, B. D. Rouhani, and P. Nikfard, “A Review of Critical Success Factors of Enterprise Architecture Implementation," in 2013 International Conference on Informatics and Creative Multimedia, 2013, pp. 38-42.

[48] M. Janssen and G. Kuk, “Complex Adaptive System Perspective of Enterprise Architecture in Electronic Government," 39th Hawaii International Conference on System Sciences (HICSS-39). Computer Societry Press, Kauai, p. $71 b(1-10), 2006$.

[49] H. Lueders, "Interoperability and Open Standards for eGovernment Services,” in Proc. of First eGovernment Interoperablility Conference, 2005, pp. 1-9.

[50] F. Almeida, J. Oliveira, and J. Cruz, "Open Standards and Open Source: Enabling Interoperability,” Int. J. Softw. Eng. Appl., vol. 2, no. 1, pp. 1-11, 2011.

[51] T.-M. Yang and T. A. Pardo, "How Is Information Shared across Boundaries?,” in 44th Hawaii International Conference on System Sciences (HICSS-44), 2011, vol. 0, pp. 1-10.

[52] G. Misuraca, G. Alfano, and G. Viscusi, “Interoperability Challenges for ICT-enabled Governance: Towards a panEuropean Conceptual Framework,” J. Theor. Appl. Electron. Commer. Res., vol. 6, no. 1, pp. 95-111, 2011.

[53] R. Klischewski and H. J. Scholl, "Information Quality as a Common Ground for Key Players in e-Government Integration and Interoperability,” 39th Hawaii International Conference on System Sciences (HICSS-39). Computer Society Press, Kauai, p. 72 (1-10), 2006.

[54] R. K. Mitchell, B. R. Agle, and D. J. Wood, “Toward a Theory of Stakeholder Identification and Salience: Defining the Principle of Who and What Really,” Acad. Manag. Rev., vol. 22, no. 4, pp. 853-886, 1997.

[55] K. Penttinen and H. Isomäki, “Stakeholders' views on government enterprise architecture: strategic goals and new public services," 1st International Conference on Electronic government and the Information Systems Perspective (EGOVIS 2010), vol. 6267. Springer-Verlag, Bilbao, Spain, pp. 1-8, 2010. 